\title{
Estimating need for alcohol treatment in Ireland using national treatment surveillance data
}

\author{
Anne Marie Carew ${ }^{1}\left[\right.$ D $\cdot$ Derek O'Neill $^{1} \cdot$ Suzi Lyons ${ }^{1} \cdot$ Bobby P. Smyth $^{2}$
}

Received: 2 June 2021 / Accepted: 17 September 2021 / Published online: 3 October 2021

(c) The Author(s) 2021

\begin{abstract}
Background International evidence indicates that about $10 \%$ of people with alcohol dependence will seek and commence treatment each year. Based upon Irish estimates of prevalence of dependence, a target of 690.0 treated cases per 100,000 population per annum is expected.

Aims This study analyses routine national surveillance data on alcohol treatment to measure how treatment need is being met. Methods National treatment surveillance data on problem alcohol use collected by the National Drug Treatment Reporting System (NDTRS) were analysed. The study included cases resident in Ireland, aged 18-64 years entering treatment for alcohol use disorder (AUD) between 2015 and $2019(n=44,079)$. Treatment rates were calculated per 100,000 of the population. Descriptive and exploratory statistics were used to describe characteristics of cases treated.

Results National rate of treated AUD was 270 cases per 100,000 annually, with a rate of treated alcohol dependence of $165 / 100,000$. There was a fivefold difference between the lowest and highest rates (119 cases per 100,000 in Meath versus 633 in Waterford). Drinking patterns indicate high levels of alcohol consumption and prolonged use prior to treatment. The use of other drugs alongside alcohol was common.

Conclusions Despite high rates of alcohol consumption and dependence, the rate of treatment entry nationally is sub-optimal, although there are wide geographic variations. There is a need to better understand the reasons for low treatment entry rates in Ireland for people with alcohol dependence. Monitoring and surveillance play a key role in measuring the successful efforts to reduce the harm of alcohol.
\end{abstract}

Keywords Alcohol $\cdot$ Service planning $\cdot$ Treatment $\cdot$ Treatment need

\section{Background}

Alcohol use is the is the leading risk factor among those aged 15-49 years for both deaths and disability-adjusted life years globally [1]. Ireland has one of the highest per-capita alcohol consumption rates in the European Union, with levels of alcohol consumption and hazardous drinking patterns in Ireland projected to increase over the next decade [2]. The most recently available Irish figures estimate that among the general population, $6.9 \%$ are alcohol-dependent [3].

Anne Marie Carew

amcarew@hrb.ie

1 Health Research Board, Grattan House, 67-72 Lower Mount Street, Dublin D02 H638, Ireland

2 Department of Public Health \& Primary Care, Trinity College Dublin, Dublin, Ireland
One complication when discussing treatment of alcohol problems relates to international differences in diagnostic categories. ICD 11 continues to distinguish two separate categories of problematic alcohol use, these being alcohol dependence and harmful alcohol use. DSM V has in recent years moved towards use of the single term of alcohol use disorder (AUD), this being rated on a spectrum from mild to severe [4].

Public health measures across the entire population are important in trying to reduce alcohol-related harm across Ireland [5], and high-quality accessible treatment for people with AUD is vital. Internationally, there is evidence that many people with an AUD fail to recognise their drinking as problematic [6-11]. This may be even more common in Ireland where just $16 \%$ of dependent drinkers in population samples recognise that they are drinking heavily [12]. Studies show that the annual rate of access to specialist treatment for AUD is about $10 \%$ [13]. With an estimated population 
prevalence of $6.9 \%$ alcohol-dependent, the target of treating $10 \%$ per annum suggests that there should be about 690 episodes of treated alcohol dependence per 100,000 adults each year in Ireland.

Although dependence and drinking frequency are strong predictors of treatment entry [14], the literature shows that there is a strong association between perceived need and use of services [15-21], with indications that $8.5-22.8 \%$ of people with substance use disorder perceiving a need for treatment $[15,21]$. However, the proportion of people who both recognise that they need treatment and also take the step of seeking it out can be as low as 3\% [22] to 6\% [23].

In order to provide appropriate and adequate access to treatment for AUD in the population, it is imperative to understand the level of need and demand. Understanding the geographical distribution of treatment need is also crucial in establishing and maintaining adequate service levels. Some of the ways this can be achieved is through surveys looking at levels of alcohol consumption within the general population which can help predict levels of need [3, 12]. Treatment data can also be another useful source of information to assist in understanding the level of need. Not only is there a range of effective treatments available to address AUD, treatment is cost-effective [24, 25]. In Ireland, the range of treatment, rehabilitation, and recovery services are provided using a four-tier model of care [26] allowing the individual to access supports at the level of complexity that reflects their situation and needs [27], with more severe AUD directed to tier 3 (specialist outpatient addiction services) and tier 4 (residential) services. The majority of cases treated for AUD in Ireland attend outpatient settings [28].

The aim of this study was to determine the rate of treated AUD in the Irish population using routinely gathered health surveillance data to aid the planning and provision of adequate service provision.

\section{Methods}

The study is a secondary analysis of routinely gathered health surveillance data from the Irish National Drug Treatment Reporting System (NDTRS). The NDTRS is a national register of addiction treatment in Ireland [29] and data is collected following the European TDI protocol, available at http://www.emcdda.europa.eu/publications/manuals/tdiprotocol-3.0_en. Treatment data are provided by statutory and non-statutory services, including outpatient services, residential centres, and prisons. Data on opioid substitution provided by general practitioners (GPs) is also included. The NDTRS is considered a comprehensive measure of treatment demand nationally and includes data from public, voluntary, and private treatment services in receipt of public funds [30]. NDTRS data coverage (numbers of admissions and treatment centres reporting data) is high [31], particularly in inpatient, outpatient, and low threshold settings [30]. Service providers collect data including client demographic and socioeconomic information, referral and assessment details, current problem drugs (up to four substances), treatment history, injecting risk behaviours, treatment interventions provided, and details of treatment outcome at the time of discharge or transfer to another service. The NDTRS records episodes, or cases of treatment as there is currently no national system-wide unique identifier in the Irish health system; in any given year, individuals may appear more than once if treated in different centres or if they return to treatment in the same centre. The study population included all cases resident in Ireland who entered treatment for problem use of alcohol in the period 2015-2019. Cases aged 18-64 years of age that reported alcohol as either their main or an additional problem drug were included $(n=44,079)$.

Rates of treatment entry were calculated per 100,000 of the population per annum based on census 2016 and use of published estimates for other years [32, 33]. A combination of descriptive, exploratory statistics was used to describe characteristics of cases treated for alcohol use. Appropriate measures were reported depending on data distributions. Data were managed and analysed in the Statistical Package for Social Sciences (SPSS), version 26.0 [34].

\section{Results}

\section{Profile of cases entering treatment}

A total of 44,079 cases entered treatment for problem alcohol use during the period 2015-2019. Of these, 34,836 (79.0\%) cases had alcohol as a main problem, while $9243(21.0 \%)$ cases had alcohol as an additional problem (Table 1). The majority of cases were male (67.4\%). In cases where alcohol was the main problem drug, the age profile was older, with $1.3 \%$ aged less than 20 years compared to $8.0 \%$ of cases where alcohol was an additional problem drug. Almost onein-four $(24.4 \%)$ had ceased their education before their sixteenth birthday and unemployment was common. The most common source of referral was self-referral $(40.5 \%)$, while $11.6 \%$ were referred to treatment by family or friends; $23.0 \%$ were health-related referrals (general practitioners/hospital or other medical settings, $10.7 \%$ were referred by social services and $2.9 \%$ were referred by the criminal justice system). The median age of first use of alcohol and other drugs was 15 years. A substantial proportion $(41.8 \%)$ were new treatment cases and had never been treated for alcohol use previously. The majority (61.2\%) were alcohol-dependent.

Consumption levels were high with half of episodes consuming 12 standard drinks on a typical drinking day. Drinking patterns indicate prolonged alcohol use prior to 
Table 1 Profile of cases seeking treatment for AUD

\begin{tabular}{|c|c|c|c|c|c|c|}
\hline \multirow[t]{2}{*}{ Variable } & \multicolumn{2}{|c|}{$\begin{array}{l}\text { Alcohol as a main } \\
\text { problem }\end{array}$} & \multicolumn{2}{|c|}{ Alcohol as an additional problem } & \multicolumn{2}{|l|}{ Total } \\
\hline & $N=34,836$ & $\%$ & $N=9243$ & $\%$ & $N=44,079$ & $\%$ \\
\hline \multicolumn{7}{|l|}{ Sex } \\
\hline Male & 22,711 & $65.2 \%$ & 7001 & $75.7 \%$ & 29,712 & $67.4 \%$ \\
\hline Female & 12,041 & $34.6 \%$ & 2216 & $24.0 \%$ & 14,257 & $32.3 \%$ \\
\hline Unknown & 84 & $0.2 \%$ & 26 & $0.3 \%$ & 110 & $0.2 \%$ \\
\hline \multicolumn{7}{|l|}{ Age group } \\
\hline $15-19$ & 93 & $1.3 \%$ & 161 & $8.0 \%$ & 254 & $2.8 \%$ \\
\hline $20-24$ & 431 & $6.1 \%$ & 407 & $20.3 \%$ & 838 & $9.3 \%$ \\
\hline $25-29$ & 702 & $10.0 \%$ & 423 & $21.1 \%$ & 1125 & $12.5 \%$ \\
\hline $30-34$ & 911 & $13.0 \%$ & 360 & $18.0 \%$ & 1271 & $14.1 \%$ \\
\hline $35-39$ & 1147 & $16.3 \%$ & 305 & $15.2 \%$ & 1452 & $16.1 \%$ \\
\hline $40-44$ & 1079 & $15.4 \%$ & 183 & $9.1 \%$ & 1262 & $14.0 \%$ \\
\hline $45-49$ & 949 & $13.5 \%$ & 92 & $4.6 \%$ & 1041 & $11.5 \%$ \\
\hline $50-64$ & 1708 & $24.3 \%$ & 70 & $3.5 \%$ & 1778 & $19.7 \%$ \\
\hline \multicolumn{7}{|l|}{ Education } \\
\hline Primary level incomplete & 520 & $1.5 \%$ & 176 & $1.9 \%$ & 696 & $1.6 \%$ \\
\hline Primary level & 4195 & $12.0 \%$ & 1353 & $14.6 \%$ & 5548 & $12.6 \%$ \\
\hline Junior cert & 10,114 & $29.0 \%$ & 3403 & $36.8 \%$ & 13,517 & $30.7 \%$ \\
\hline Leaving cert & 11,644 & $33.4 \%$ & 2771 & $30.0 \%$ & 14,415 & $32.7 \%$ \\
\hline Third level & 5034 & $14.5 \%$ & 631 & $6.8 \%$ & 5665 & $12.9 \%$ \\
\hline Never went to school & 64 & $0.2 \%$ & 9 & $0.1 \%$ & 73 & $0.2 \%$ \\
\hline Not known & 3265 & $9.4 \%$ & 900 & $9.7 \%$ & 4165 & $9.4 \%$ \\
\hline \multicolumn{7}{|l|}{ Age ceased education } \\
\hline Before 16 years & 8068 & $23.2 \%$ & 2695 & $29.2 \%$ & 10,763 & $24.4 \%$ \\
\hline \multicolumn{7}{|l|}{ Employment } \\
\hline Employed & 9620 & $27.6 \%$ & 1866 & $20.2 \%$ & 11,486 & $26.1 \%$ \\
\hline Unemployed & 19,355 & $55.6 \%$ & 5450 & $59.0 \%$ & 24,805 & $56.3 \%$ \\
\hline Student & 565 & $1.6 \%$ & 265 & $2.9 \%$ & 830 & $1.9 \%$ \\
\hline Other & 4730 & $13.6 \%$ & 1426 & $15.4 \%$ & 6156 & $14.0 \%$ \\
\hline Not known & 566 & $1.6 \%$ & 236 & $2.6 \%$ & 802 & $1.8 \%$ \\
\hline \multicolumn{7}{|l|}{ Living where } \\
\hline Stable accommodation & 29,017 & $83.3 \%$ & 7013 & $75.9 \%$ & 36,030 & $81.7 \%$ \\
\hline Homeless & 3126 & $9.0 \%$ & 808 & $8.7 \%$ & 3934 & $8.9 \%$ \\
\hline Other unstable accommodation & 937 & $2.7 \%$ & 259 & $2.8 \%$ & 1196 & $2.7 \%$ \\
\hline Prison & 711 & $2.0 \%$ & 707 & $7.6 \%$ & 1418 & $3.2 \%$ \\
\hline Residential care/halfway house & 648 & $1.9 \%$ & 320 & $3.5 \%$ & 968 & $2.2 \%$ \\
\hline Not known & 397 & $1.1 \%$ & 136 & $1.5 \%$ & 533 & $1.2 \%$ \\
\hline \multicolumn{7}{|l|}{ Living arrangements } \\
\hline Alone & 8170 & $23.5 \%$ & 1113 & $12.0 \%$ & 9283 & $21.1 \%$ \\
\hline Parents and family & 9321 & $26.8 \%$ & 3987 & $43.1 \%$ & 13,308 & $30.2 \%$ \\
\hline Friends & 838 & $2.4 \%$ & 261 & $2.8 \%$ & 1099 & $2.5 \%$ \\
\hline With partner & 3462 & $9.9 \%$ & 490 & $5.3 \%$ & 3952 & $9.0 \%$ \\
\hline Partner and child & 5863 & $16.8 \%$ & 964 & $10.4 \%$ & 6827 & $15.5 \%$ \\
\hline Alone with child & 2252 & $6.5 \%$ & 358 & $3.9 \%$ & 2610 & $5.9 \%$ \\
\hline Other & 4433 & $12.7 \%$ & 1876 & $20.3 \%$ & 6309 & $14.3 \%$ \\
\hline Not known & 497 & $1.4 \%$ & 194 & $2.1 \%$ & 691 & $1.6 \%$ \\
\hline \multicolumn{7}{|l|}{ Dependent children } \\
\hline Living with dependent children & 8115 & $23.3 \%$ & 1322 & $14.3 \%$ & 9437 & $21.4 \%$ \\
\hline
\end{tabular}


Table 1 (continued)

\begin{tabular}{|c|c|c|c|c|c|c|c|}
\hline \multicolumn{8}{|l|}{ Region } \\
\hline Dublin & 8745 & $25.1 \%$ & 2863 & $31.0 \%$ & & 11,608 & $26.3 \%$ \\
\hline Rest of Ireland & 25,894 & $74.3 \%$ & 6328 & $68.5 \%$ & & 32,222 & $73.1 \%$ \\
\hline Ireland unknown & 197 & $0.6 \%$ & 52 & $0.6 \%$ & & 249 & $0.6 \%$ \\
\hline \multicolumn{8}{|l|}{ Source of referral } \\
\hline Self & 14,214 & $40.8 \%$ & 3654 & $39.5 \%$ & & 17,868 & $40.5 \%$ \\
\hline Family and friends & 3992 & $11.5 \%$ & 1127 & $12.2 \%$ & & 5119 & $11.6 \%$ \\
\hline Other drug treatment centre & 2185 & $6.3 \%$ & 1180 & $12.8 \%$ & & 3365 & $7.6 \%$ \\
\hline General practitioner & 4399 & $12.6 \%$ & 519 & $5.6 \%$ & & 4918 & $11.2 \%$ \\
\hline Hospital or other medical source & 4591 & $13.2 \%$ & 604 & $6.5 \%$ & & 5195 & $11.8 \%$ \\
\hline Social services & 3691 & $10.6 \%$ & 1017 & $11.0 \%$ & & 4708 & $10.7 \%$ \\
\hline Court/probation/police & 873 & $2.5 \%$ & 422 & $4.6 \%$ & & 1295 & $2.9 \%$ \\
\hline Other & 668 & $1.9 \%$ & 650 & $7.0 \%$ & & 1318 & $3.0 \%$ \\
\hline Not known & 223 & $0.6 \%$ & 70 & $0.8 \%$ & & 293 & $0.7 \%$ \\
\hline \multicolumn{8}{|l|}{ Extent of drinking problem } \\
\hline Hazardous & 3307 & $9.5 \%$ & 2347 & $25.4 \%$ & & 5654 & $12.8 \%$ \\
\hline Harmful & 5894 & $16.9 \%$ & 2663 & $28.8 \%$ & & 8557 & $19.4 \%$ \\
\hline Dependent & 23,808 & $68.3 \%$ & 3423 & $37.0 \%$ & & 27,231 & $61.8 \%$ \\
\hline Not known & 1827 & $5.2 \%$ & 810 & $8.7 \%$ & & 2637 & $6.0 \%$ \\
\hline Consumption on a typical drinking day & \multicolumn{7}{|c|}{ Median (25th,75th percentile) } \\
\hline $\begin{array}{l}\text { Number of standard drinks (among those } \\
\text { consuming alcohol in the month prior to } \\
\text { treatment) }\end{array}$ & \multicolumn{2}{|c|}{$16(6,36)$} & \multicolumn{3}{|l|}{$15(5,32)$} & \multicolumn{2}{|l|}{$16(6,35)$} \\
\hline Duration of use & \multicolumn{7}{|c|}{ Median (25th,75th percentile) } \\
\hline Years prior to first-treatment & $23(6,42)$ & & $13(4,30)$ & & & $21(5,42)$ & \\
\hline \multicolumn{8}{|l|}{ Treatment status } \\
\hline New alcohol treatment cases & 15,828 & $45.4 \%$ & 2612 & & $28.3 \%$ & 18,440 & $41.8 \%$ \\
\hline \multicolumn{8}{|l|}{ Polydrug use } \\
\hline More than one problem drug & 7056 & $20.3 \%$ & 9243 & & $100.0 \%$ & 16,299 & $37.0 \%$ \\
\hline Problem drug use & \multicolumn{2}{|c|}{$\begin{array}{r}\text { Additional problem } \\
\quad \operatorname{drugs}^{\wedge}(n=7056)\end{array}$} & \multicolumn{3}{|c|}{$\begin{array}{l}\text { Main problem drug where alcohol was an addi- } \\
\text { tional problem }\end{array}$} & & \\
\hline Cannabis & 4083 & $57.9 \%$ & 2276 & & $24.6 \%$ & & \\
\hline Cocaine & 3082 & $43.7 \%$ & 2825 & & $30.6 \%$ & & \\
\hline Benzodiazepines & 1728 & $24.5 \%$ & 1183 & & $12.8 \%$ & & \\
\hline Opioids & 1005 & $14.2 \%$ & 2409 & & $26.1 \%$ & & \\
\hline Ecstasy & 659 & $9.3 \%$ & 69 & & $0.7 \%$ & & \\
\hline Amphetamines & 258 & $3.7 \%$ & 68 & & $0.7 \%$ & & \\
\hline NPS & 104 & $1.5 \%$ & 67 & & $0.7 \%$ & & \\
\hline $\mathrm{Z}$ drugs & 132 & $1.9 \%$ & 63 & & $0.7 \%$ & & \\
\hline Other drugs & 271 & 3.8 & 283 & & 3.1 & & \\
\hline Waiting times for treatment & \multicolumn{7}{|c|}{ Median (25th,75th percentile) } \\
\hline \multirow[t]{2}{*}{ Referral to treatment start (days) } & $4(0,54)$ & & $4(0,58)$ & & & $4(0,55)$ & \\
\hline & \multicolumn{5}{|c|}{ Median (25th,75th percentile) } & & \\
\hline Age first alcohol use & $15(12,21)$ & & $14(11,18)$ & & & $15(12,21)$ & \\
\hline
\end{tabular}

${ }^{\wedge}$ Cases where alcohol was the main problem drug. Up to four additional problem drugs may be reported

seeking treatment (median duration of use prior to first treatment $=21$ years). Overall, $37.0 \%$ reported problem use of at least one other drug. Among those with alcohol as a main problem, $20.3 \%$ reported problem use of other drugs. The most common additional problem drugs were cannabis, followed by cocaine and benzodiazepines. For those cases for whom alcohol was an additional problem, cocaine, opioids, and cannabis were the most common main problem drugs. The median time between referral and treatment start was 4 days. 


\section{Rates of treatment}

In the period 2015-2009, national annual rate of treated AUD (all cases) was 270 cases per 100,000 of the 18-64-year-old population. When looking specifically at those who were identified as alcohol-dependent when treated, the rate drops to $165 / 100,000$ per annum. The analysis by county of residence (Fig. 1) shows that in the period 2015-2019 the treatment rates were highest in Waterford, Donegal, and Sligo (with more than 500 cases per 100,000 per annum), and lowest in Meath, Roscommon, Mayo, and Kildare (with less than 150 cases per 100,000 per annum). There was a fivefold difference between the lowest and highest treatment rates (119 per 100,000/annum in Meath versus 633 in Waterford). A total of twelve counties had treatment rates which were below the national rate, while in counties Meath and Roscommon, the rate was less than half that of the national rate.

\section{Discussion}

This study indicates a national rate for treated AUD is 270 cases per 100,000 population per annum. If data is confined to treated cases with alcohol dependence, the rate of treatment entry is just $165 / 100,000$ per annum. These figures fall well short of the identified target of 690 treatment episodes

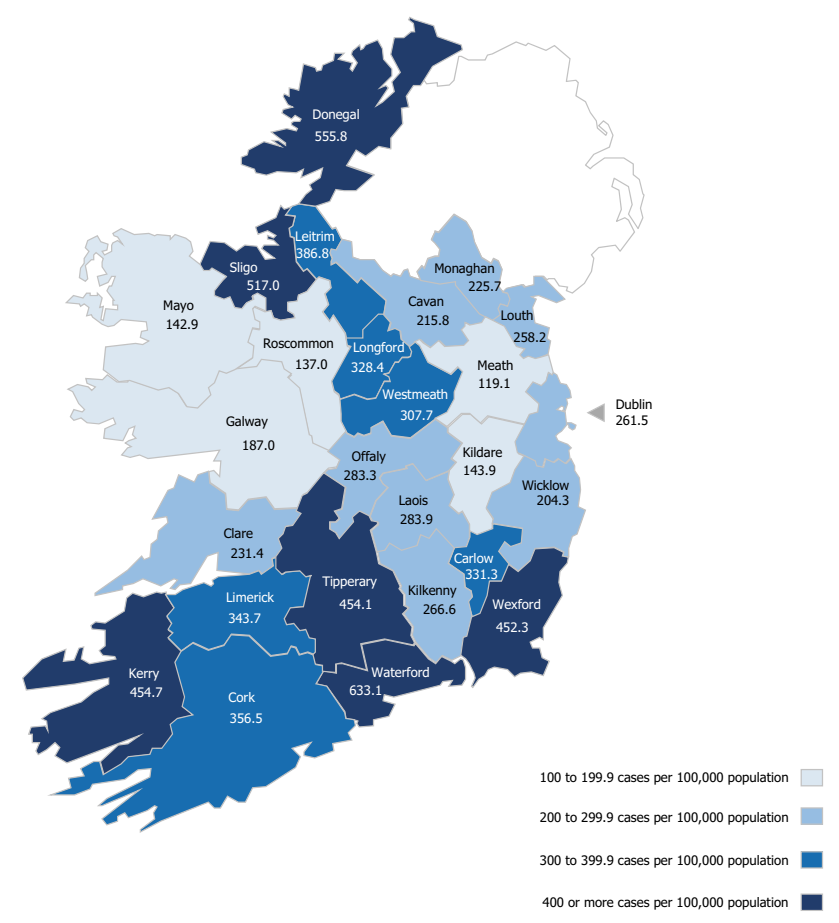

Fig. 1 Average annual prevalence of treated AUD per 100,000 population, by county of residence (NDTRS 2015-2019; CSO 2016) for dependent drinkers per 100,000 adults per annum. If the population prevalence of alcohol dependence in adults is correct, these findings suggest that only $2-3 \%$ of those with dependence are entering treatment each year. The literature recognises that there are 'hidden' populations, along with many reasons for seeking treatment [14] or not seeking treatment [14, 35-37]. Nonetheless, studies show that there is a strong association between perceived need and use of services [15-21], with indications that $8.5-22.8 \%$ of people with substance use disorder perceiving a need for treatment $[15,21]$.

Our Irish treatment target (690/100,000 population) is based on the best estimate of the population prevalence and on rates of treatment engagement in the international literature. The target is lower in comparison to similar rates reported in the literature [38, 39]. However, a recent study from the USA found that AUD was the most common substance use disorder and among those with AUD past-year treatment use was 6.3\% (CI: 5.49-7.18) [23], while earlier studies from other countries report rates of below or near $10 \%$ [40-43]. We opted to set the target for Ireland at 10\% in this study as there are differences in study methodology or inclusion criteria. For example, some treatment entry figures in international studies include attendance at services such as alcoholics anonymous and primary care GPs which are not reported in NDTRS alcohol treatment figures. Nonetheless, our target figure for treated alcohol dependence for Ireland is not unrealistic given that it is below that reported for other countries.

Although the national rate of treatment entry was lower than the target rate, there is substantial geographical variation. There was a fivefold difference in rates contrasting the counties with the highest rates of treatment entry with the lowest rates. According to the latest available survey of the population, the prevalence of past-year alcohol use by people aged over 15 years ranged between 67 and $83 \%$ across Ireland [44]. Therefore, some regional variation in levels of alcohol consumption in this study is expected but it is unlikely that this variation is the sole cause of such large differences in treatment entry. In fact, the area with the lowest last year drinking prevalence of $67 \%$ has the some of the highest rates of treatment entry (Donegal, Sligo, Leitrim) [44].

It is possible that the variance in treatment availability by county may be influenced by local service provider participation in the NDTRS. There are high levels of service provider coverage in the NDTRS [31]; nonetheless, not all eligible treatment services participate. Over the last 6 years, the number of services participating in the NDTRS has remained steady at approximately 600 services [30]. However, NDTRS coverage varies by HSE CHO area and this may explain some of the observed variation in rates. For example, coverage of services in CHO 3 (Clare, Limerick, 
and North Tipperary/East Limerick areas) is below the national average with just $65 \%$ of treatment services located in this region actively participating in the NDTRS, while just 59\% of services located in CHO 6 (Wicklow, Dun Laoghaire, and Dublin South East areas) actively participate in the NDTRS [30]. It is encouraging that treatment rates in some counties were approaching the target rate and indicates that it is possible to attain acceptable rates of treatment entry in an Irish context. This study cannot shed light on why those counties achieved such success while others appear to be failing to meet to the needs of adults with alcohol dependence. There are substantial benefits to routine alcohol screening, early intervention, and referral to treatment [45]. Alcohol treatment is effective in reducing harms and it is cost-effective [24, 25]. In order to reduce alcohol-related harms and support recovery, the obstacles to treatment entry should be better understood and treatment capacity increased where it is a limiting factor in treatment entry. Planning projections for clinical services involved in the treatment of alcohol use disorders should be informed by population need rather than historic levels of provision [38].

Past evidence indicates that most dependent drinkers in Ireland fail to describe their own alcohol use as heavy drinking [12], and many Irish drinkers have a poor understanding of low-risk drinking patterns. Consequently, it seems highly likely that many with alcohol dependence have not even contemplated a need for treatment [9]. Efforts to improve understanding of harmful patterns of drinking across the population may have the double benefit of reducing use and simultaneously increasing treatment seeking among the subset of drinkers who are dependent.

A person's pattern of drinking is an important determinant of alcohol-related harm [12]. The NDTRS data shows that alcohol consumption levels were high, showing frequent risky single occasion drinking (RSOD), or binge drinking. Given that two-in-three cases were already alcohol-dependent before seeking treatment, more needs to be done to understand and address these delays. This drinking pattern is associated with a number of negative health, social, and economic consequences including liver cirrhosis, various types of cancer, increased likelihood of driving under the influence of alcohol, intentional self-harm, injury, and risky sexual behaviours [46-49]. These results also suggest that further work is required to educate the Irish public on low-risk drinking limits and it may be useful to introduce low-risk daily limits.

The median age of first use of alcohol and other drugs was 15 years which is not surprising given the decline in age of first drinking over past 40 years in Ireland [50]. This supports the need to delay the initiation to drinking among young people to reduce alcohol-related harm particularly as it is a known risk factor for later alcohol dependence [51]. NDTRS data will enable policymakers to measure the impact of any policy changes and may allow health service planners to allocate appropriate resources to the treatment of problem alcohol use.

The association between alcohol and additional problem substances was examined as information about the combinations of substances used is important in terms of individual clients' care plans. Over a third of all cases reported problems with other drugs. Cannabis was the most commonly reported substance used alongside alcohol while cocaine was the second most commonly reported substance used alongside alcohol. This is not unexpected as cannabis is the most common drug used in the population as per the general population survey, and the general population study also showed the relationship between cannabis and alcohol use [52]. A recent study of substance use disorder comorbidity combinations shows that not only does alcohol feature in the four most common comorbidity combinations, alcohol and cannabis use disorder was also the most common comorbidity combination and this combination had the lowest receipt of treatment [23]. These data highlight the association between alcohol and other substances and the need for an integrated approach to the management of the full range of substance use disorders in Ireland.

\section{Strengths and limitations}

Data on treated alcohol cases from the NDTRS continue to provide valuable information which allows alcohol and drug services to understand the extent of the problem, the personal and substance-using characteristics of those seeking treatment, and trends in treatment seeking over time. These data enable health service planners to allocate appropriate resources to the treatment of problem alcohol use. Population characteristics may not generalise beyond the treatment seeking population. Within the NDTRS, it is possible that individuals may appear more than once if they have more than one treatment within a single calendar year. In the absence of a national system-wide unique identifier in the Irish health system, it is not possible to accurately distinguish between cases and individuals. It also does not include those who were treated via entry into mutual selfhelp programmes such as AA or treated by their GPs only.

Despite these high levels of service provider coverage by NDTRS [31], not all treatment services participate in the system. Therefore, it is possible that the variance in treatment availability by county may be influenced by local service provider participation in the NDTRS. Notwithstanding the Health Research Board's best efforts and also the requirement for all publicly funded services to make NDTRS returns [53], some alcohol treatment services managed by the addiction and mental health services do not participate. For this reason, coverage of cases remains incomplete in counties Dublin, Galway, Mayo, the Midlands (Laois, Offaly, 
Longford, Westmeath), and North East (Cavan, Monaghan, Louth, and Meath). Rates may also be affected by the availability of alcohol-specific services. It may therefore be assumed that the data presented in this paper underestimate the true extent of treated AUD in Ireland. In Ireland, those with substance use disorder may access inpatient treatment in psychiatric hospitals and these cases are not recorded by the NDTRS. In 2019, 1090 cases admitted to psychiatric inpatient facilities with an alcohol disorder, with trends over time indicating an overall decline in such admissions, which only slightly alters the proportion of those with AUD receiving treatment [54]. Nonetheless, data regarding outpatient treatments from such psychiatric hospitals is not returned to the NDTRS, despite best efforts of the Health Research Board to secure such data.

\section{Implications}

There is a need to urgently address the relatively low rate of entry into treatment by people with alcohol dependence in Ireland. Efforts must be undertaken to better understand this service failure. There seem to be issues with problem recognition among affected individuals and there may also be unknown barriers and obstacles to treatment seeking among those who perceive a need for treatment. The general population survey of alcohol and drug use may offer an opportunity to explore these issues in the future.

As stated in Ireland's current National Drugs Strategy, there is a need for all treatment providers to fully participate in the NDTRS system, so that the real extent of under-treatment can be comprehensively examined. There is substantial geographical variability in the recorded rate of treatment entry. There is a need for services in counties with low rates of treatment entry to learn from the successes of those in locations with acceptable levels of treatment entry.

\section{Conclusions}

The proportion of people with alcohol dependence who enter treatment each year is low by international standards, and there is wide and unexplained geographical variation in rates of treatment attendance. There appears to be a need to better plan the provision of treatment services, so treatment is available where and when people seek it, with opportunities to learn from locations with higher rates of treatment entry. Strategies for early identification of AUD, such as the Making Every Contact Count initiative across all healthcare settings, may result in greater treatment seeking in the near future.

Acknowledgements The Health Research Board provided the dataset used in this study. The authors would like to thank the Health Research
Board, the NDTRS team, and all the services who provide NDTRS data.

Author contribution B.S. conceived of the study. AM.C. analysed the data and wrote a first draft of the manuscript. All authors interpreted the data and edited and approved the final manuscript.

Availability of data and material The data used is available on request from the Health Research Board.

Code availability Data were managed and analysed in the Statistical Package for Social Sciences (SPSS), version 26.0. Code is available on request.

\section{Declarations}

Ethics approval The analyses presented here used routinely collected and anonymized secondary data; study-specific consent was, therefore, not required.

Conflict of interest The authors declare no competing interests.

Open Access This article is licensed under a Creative Commons Attribution 4.0 International License, which permits use, sharing, adaptation, distribution and reproduction in any medium or format, as long as you give appropriate credit to the original author(s) and the source, provide a link to the Creative Commons licence, and indicate if changes were made. The images or other third party material in this article are included in the article's Creative Commons licence, unless indicated otherwise in a credit line to the material. If material is not included in the article's Creative Commons licence and your intended use is not permitted by statutory regulation or exceeds the permitted use, you will need to obtain permission directly from the copyright holder. To view a copy of this licence, visit http://creativecommons.org/licenses/by/4.0/.

\section{References}

1. Griswold MGFN, Hawley C, Arian N, Zimsen SR et al (2018) Alcohol use and burden for 195 countries and territories, 19902016: a systematic analysis for the Global Burden of Disease Study 2016. Lancet (London, England) 392(10152):1015-1035. https://doi.org/10.1016/s0140-6736(18)31310-2

2. Manthey J, Shield KD, Rylett M et al (2019) Global alcohol exposure between 1990 and 2017 and forecasts until 2030: a modelling study. Lancet (London, England) 393(10190):2493-2502. https:// doi.org/10.1016/s0140-6736(18)32744-2

3. Long J, Mongan D (2014) Alcohol consumption in Ireland 2013: analysis of a national alcohol diary survey. Health Research Board, Dublin

4. Saunders JB, Peacock A, Degenhardt L (2018) Alcohol use disorders in the draft ICD-11, and how they compare with DSM5. Curr Addict Rep 5(2):257-264. https://doi.org/10.1007/ s40429-018-0197-8

5. Government of Ireland (2018) Public Health (Alcohol) Act 2018. Government of Ireland, Ireland

6. Bendtsen P, Karlsson N, Dalal K, Nilsen P (2011) Hazardous drinking concepts, limits and methods: low levels of awareness, knowledge and use in the Swedish population. Alcohol and alcoholism (Oxford, Oxfordshire) 46(5):638-645. https://doi.org/10. 1093/alcalc/agr065 
7. Foundation for Alcohol Research and Education (2019) 2019 Annual Alcohol Poll. FARE, Deakin

8. Mongan D, Long J (2015) Standard drink measures throughout Europe; peoples' understanding of standard drinks and their use in drinking guidelines, alcohol surveys and labelling. Health Research Board, Dublin

9. Ipsos MRBI (2012) Alcohol: public knowledge, attitudes and behaviours. Health Research Board, Dublin

10. Buykx P, Li J, Gavens L et al (2018) Self-reported knowledge, correct knowledge and use of UK drinking guidelines among a representative sample of the English population. Alcohol and alcoholism (Oxford, Oxfordshire) 53(4):453-460. https://doi.org/ 10.1093/alcalc/agx127

11. Bowden JA, Delfabbro P, Room R et al (2014) Alcohol consumption and NHMRC guidelines: has the message got out, are people conforming and are they aware that alcohol causes cancer? Aust N Z J Public Health 38(1):66-72. https://doi.org/10.1111/17536405.12159

12. Mongan D, Millar SR, O'Dwyer C et al (2020) Drinking in denial: a cross-sectional analysis of national survey data in Ireland to measure drinkers' awareness of their alcohol use. BMJ Open 10(7):e034520. https://doi.org/10.1136/bmjopen-2019-034520

13. Brennan A, Hill-McManus D, Stone T et al (2019) Modeling the potential impact of changing access rates to specialist treatment for alcohol dependence for local authorities in England: the Specialist Treatment for Alcohol Model (STreAM). J Studies on Alcohol and Drugs, Supplement (s18):96-109. https://doi.org/10. 15288/jsads.2019.s18.96

14. Storbjörk J, Room R (2008) The two worlds of alcohol problems: who is in treatment and who is not? Addiction Research \& Theory 16(1):67-84. https://doi.org/10.1080/16066350701578136

15. Mojtabai R, Crum RM (2013) Perceived unmet need for alcohol and drug use treatments and future use of services: results from a longitudinal study. Drug Alcohol Depend 127(1-3):59-64. https:// doi.org/10.1016/j.drugalcdep.2012.06.012

16. Edlund MJ, Unützer J, Curran GM (2006) Perceived need for alcohol, drug, and mental health treatment. Soc Psychiatry Psychiatr Epidemiol 41(6):480-487. https://doi.org/10.1007/ s00127-006-0047-1

17. Meadows G, Burgess P, Bobevski I et al (2002) Perceived need for mental health care: influences of diagnosis, demography and disability. Psychol Med 32(2):299-309. https://doi.org/10.1017/ s0033291701004913

18. Mojtabai R, Olfson M, Mechanic D (2002) Perceived need and help-seeking in adults with mood, anxiety, or substance use disorders. Arch Gen Psychiatry 59(1):77-84. https://doi.org/10.1001/ archpsyc.59.1.77

19. Sareen J, Jagdeo A, Cox BJ et al (2007) Perceived barriers to mental health service utilization in the United States, Ontario, and the Netherlands. Psychiatric services (Washington, DC) 58(3):357-364. https://doi.org/10.1176/ps.2007.58.3.357

20. Urbanoski KA, Cairney J, Bassani DG, Rush BR (2008) Perceived unmet need for mental health care for Canadians with cooccurring mental and substance use disorders. Psychiatric services (Washington, DC) 59(3):283-289. https://doi.org/10.1176/ps. 2008.59.3.283

21. Moeller SJ, Platt JM, Wu M, Goodwin RD (2020) Perception of treatment need among adults with substance use disorders: longitudinal data from a representative sample of adults in the United States. Drug Alcohol Depend 209:107895. https://doi.org/ 10.1016/j.drugalcdep.2020.107895

22. Substance Abuse and Mental Health Services Administration (2010) National survey on drug use and health. U.S. Department of Health and Human Services, Center for Behavioral Health Statistics and Quality,
23. Von Gunten CD, Wu LT (2021) Comorbid substance use disorder profiles and receipt of substance use disorder treatment services: a national study. J Stud Alcohol Drugs 82(2):246-256

24. Heather N, Raistrick D, Godfrey C (2006) A summary of the review of the effectiveness of treatment for alcohol problems. National Treatment Agency for Substance Misuse, London

25. UKATT Research Team (2005) Cost effectiveness of treatment for alcohol problems: findings of the randomised UK alcohol treatment trial (UKATT). BMJ 331(7516):544. https://doi.org/ 10.1136/bmj.331.7516.544

26. Doyle J, Ivanovic J (2010) National Drugs Rehabilitation Framework Document. National Drugs Rehabilitation Implementation Committee. Health Services Executive, Dublin

27. Bryant-Jefferies R (2004) Models of care for drug service provision. Radcliffe Publishing Ltd, Oxford

28. Condron I, Carew A, Lyons S (2020) Alcohol treatment in Ireland 2013 to 2019. Health Research Board, Dublin

29. Health Research Board (2008) Trends in treated problem alcohol use in Ireland, 2004 to 2006. HRB Tend Series, vol HRB Trends Series. Health Research Board, Dublin

30. Bruton L, Gibney S, Hynes T et al (2021) Spending review 2021. Focused policy assessment of reducing harm, supporting recovery: an analysis of expenditure and performance in the area of drug and alcohol misuse. Government of Ireland, Dublin

31. Health Research Board (2017) Irish National Focal Point to the European Monitoring Centre for Drugs and Drug Addiction. (2017) Focal Point Ireland: national report for 2016. Health Research Board, Dublin

32. Central Statistics Office (2017) Population 2011 to 2016. Central Statistics Office, Cork

33. Central Statistics Office (2020) Population and migration estimates April 2020. Population. Central Statistics Office, Cork

34. IBM Corporation (2019) IBM SPSS Statistics for Windows. Version 26.0 edn. IBM Corporation, Armonk, NY

35. Aoun S, Pennebaker D, Wood C (2004) Assessing population need for mental health care: a review of approaches and predictors. Ment Health Serv Res 6(1):33-46

36. Caetano R (1999) The identification of alcohol dependence criteria in the general population. Addiction (Abingdon, England) 94(2):255-267. https://doi.org/10.1046/j.1360-0443.1999. 9422559.x

37. Epstein J (2002) Substance dependence, abuse, and treatment: findings from the 2000 national household survey on drug abuse. Department of Health and Human Services, Substance Abuse and Mental Health

38. Ritter A, Mellor R, Chalmers J et al (2019) Key considerations in planning for substance use treatment: estimating treatment need and demand. Journal of Studies on Alcohol and Drugs, Supplement (s18):22-30. https://doi.org/10.15288/jsads.2019.s18.22

39. Kohn R, Saxena S, Levav I, Saraceno B (2004) The treatment gap in mental health care. Bull World Health Organ 82(11):858-866

40. Cohen E, Feinn R, Arias A, Kranzler HR (2007) Alcohol treatment utilization: findings from the National Epidemiologic Survey on Alcohol and Related Conditions. Drug Alcohol Depend 86(2-3):214-221. https://doi.org/10.1016/j.drugalcdep.2006.06. 008

41. Drummond C, Deluca P, Oyefeso A et al (2009) Scottish Alcohol Needs Assessment.

42. Drummond C, Oyefeso A, Phillips T et al (2005) Alcohol needs assessment research project (ANARP). Department of Health, London

43. Edlund MJ, Booth BM, Han X (2012) Who seeks care where? Utilization of mental health and substance use disorder treatment in two national samples of individuals with alcohol use disorders. 
J Stud Alcohol Drugs 73(4):635-646. https://doi.org/10.15288/ jsad.2012.73.635

44. National Advisory Committee on Drugs and Alcohol NIDoH (2017) Prevalence of drug use and gambling in Ireland and drug use in Northern Ireland 2014/15: regional drug and alcohol task force (Ireland) and health and social care trust (Northern Ireland) results. Bulletin 2. Department of Health, Dublin

45. Babor TF, McRee BG, Kassebaum PA et al (2007) Screening, Brief Intervention, and Referral to Treatment (SBIRT). Substance Abuse 28(3):7-30. https://doi.org/10.1300/J465v28n03_03

46. Anderson P (2007) Binge drinking and Europe. Institute of Alcohol Studies, London

47. Dawson DA (2011) Defining risk drinking. Alcohol Research: Current Reviews

48. World Health Organization (2019) Global status report on alcohol and health 2018. World Health Organization,

49. World Health Organization (2004) International statistical classification of diseases and related health problems: Tabular list, vol 1. World Health Organization,

50. Smyth BP, Kelly A, Cox G (2011) Decline in age of drinking onset in Ireland, gender and per capita alcohol consumption. Alcohol and alcoholism (Oxford, Oxfordshire) 46(4):478-484. https://doi. org/10.1093/alcalc/agr047
51. Guttmannova K, Bailey JA, Hill KG et al (2011) Sensitive periods for adolescent alcohol use initiation: predicting the lifetime occurrence and chronicity of alcohol problems in adulthood. $\mathrm{J}$ Stud Alcohol Drugs 72(2):221-231. https://doi.org/10.15288/jsad. 2011.72.221

52. National Advisory Committee on Drugs and Alcohol NIDoH (2018) Prevalence of drug use and gambling in Ireland \& drug use in Northern Ireland. 2014/15 drug prevalence survey: polydrug and new psychoactive substances results. Bulletin 4. Department of Health, Dublin

53. Department of Health Ireland (2017) Reducing harm, supporting recovery. A health-led response to drug and alcohol use in Ireland 2017 - 2025. Department of Health, 2017

54. Daly A, Craig S (2020) Activities of Irish psychiatric units and hospitals 2019 main findings. Health Research Board, Dublin

Publisher's Note Springer Nature remains neutral with regard to jurisdictional claims in published maps and institutional affiliations. 